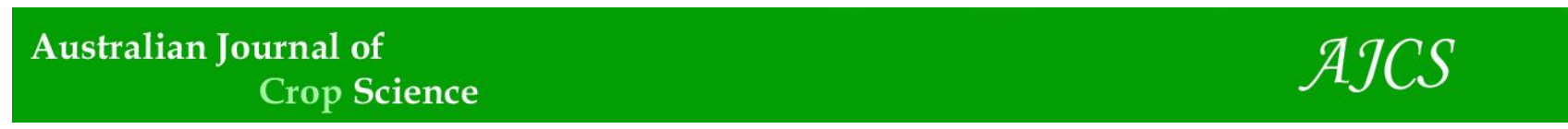

AJCS 10(5):726-731 (2016)

ISSN:1835-2707

DOI: 10.21475/ajcs.2016.10.05.p7439

\title{
Synergistic effects of BAP and kinetin media additives on regeneration of vetiver grass (Vetiveria zizanioides L. Nash)
}

\author{
Kanokporn Sompornpailin*, Chonnikarn Khunchuay
}

College of Nanotechnology, King Mongkut's Institute of Technology Ladkrabang, Bangkok, 10520, Thailand

*Correspondence author: kanokporn.so@kmitl.ac.th

\begin{abstract}
Regeneration efficiency was enhanced by adding auxin and cytokinin at different concentrations to the media. It was found that the two highest frequencies-90 and 85\%-of callus induction occured when the buds were cultured in an MS medium supplemented with $2 \mathrm{mgL}^{-1} \alpha$-naphthalene acetic acid (NAA) plus $1 \mathrm{mgL}^{-1} N^{6}$-benzylaminopurine (BAP) (CIM2) and in the same medium supplemented with $2 \mathrm{mgL}^{-1}$ NAA plus $1 \mathrm{mgL}^{-1}$ kinetin (CIM5), respectively. When cultured further in a plant regeneration medium supplemented with $1 \mathrm{mgL}^{-1} \mathrm{NAA}$ and $2 \mathrm{mgL}^{-1}$ BAP (PRM1), these calli regenerated with high efficiencies, $80 \%$ for calli grown in CIM2 and $85 \%$ for calli grown in CIM5. The low BAP concentration in CIM1 $\left(2 \mathrm{mgL}^{-1} \mathrm{NAA}\right.$ and $\left.0.5 \mathrm{mgL}^{-1} \mathrm{BAP}\right)$ resulted in a low regeneration efficiency and fewer shoots per callus even though the PRM3 regeneration medium had a high concentration of cytokinins $\left(2 \mathrm{mgL}^{-1}\right.$ BAP and $2 \mathrm{mgL}^{-1}$ kinetin). However, the calli cultured in CIM2 without kinetin but with a suitable level of BAP still regenerated with high efficiencies in PRM2 and PRM3 that contained 1 and $2 \mathrm{mgL}^{-1}$ kinetin, respectively. Similarly, when calli cultured in CIM5 without BAP but with kinetin were regenerated in PRM1 with BAP alone, they also regenerated with a high regeneration efficiency. These results showed that culturing a specific tissue in a medium with suitable concentrations of NAA and BAP or kinetin resulted in a large number of multiple shoots, and BAP and kinetin worked synergistically to produce a high plant regeneration efficiency.
\end{abstract}

Keywords: BAP, kinetin, regeneration, vetiver grass, Vetiveria zizanioides L. Nash. Abbreviations: BAP- $N^{6}$-benzylaminopurine; NAA- $\alpha$-naphthalene acetic acid; CIM-callus induction medium; PRM-plant regeneration medium.

\section{Introduction}

Vetiver grass is used for protecting the soil through moisture retention, erosion reduction, and heavy metal removal (Leauagvutiviroj et al., 2010; Minh and Khoa 2009; Sudhishri et al., 2008). In addition to soil protection, vetiver extract has been used as an ingredient in perfume and cosmetics (Bhushan et al., 2013; Bhuiyan et al., 2008). This extract is also used for controlling micro-organisms, pests, and weeds (Adam et al., 2008; Sangeetha and Stella 2012; Mao et al., 2004; Koul et al., 2008). Moreover, as a biomass, it can be used for biofuel production (Sun et al., 2014). Because of its usefulness, several countries have promoted more vetiver planting in order to support the large demand for it. Vetiver planting by a conventional method is limited by the particular climate of the plantation area; micropropagation by tissue culture is a means to resolve this problem. Tissue culture can produce large-scale sterile plantlets in a short period of time without being affected by the environment. In addition, genetic improvement of vetiver grass by molecular transformation technique requires researchers to establish a high efficiency vetiver regeneration method using tissue culture technique. In several regeneration experiments, various parts of vetiver grass have been used as an initial explant, for example, its shoot (Cedo et al., 2012), inflorescence (Sangduen and Prasertsongskun, 2009), axillary bud as well as aseptic adventitious bud (Zhenrang et al., 2006). An axillary bud was used in this study because it is easily grown under a controlled condition with minimal apical dominant effects. However, for a specific development of this bud, a certain combination of different plant growth regulators (PGRs) is usually needed. Two main groups of PGRs used in regulating somatic embryogenesis are auxins and cytokinins. Their structures are different and so are their functions. For example, auxins affect cell expansion as well as root and bud formation while cytokinins are known to regulate cell division, growth, and developmental process (Mok, 1994). According to two studies by Soni et al. (1995) and Redig et al. (1996), cytokinins enhance shoot proliferation by elevating the expression of cyclin protein that controls the division processes in Arabidopsis and tobacco cells. A combination of auxin and cytokinin has been reported to enhance the amount and quality of plant regeneration (Habiba et al., 2014; Ashraf et al., 2014). However, the molecular mechanisms that these PGRs cooperatively regulate the development of tissue are not clearly known. A relatively high concentration of auxin coupling with a dark condition is usually used in the callus induction process of monocotyledonous plants (Ali and Iqbal 2012, Sahoo et al., 2011) because auxin distributes more evenly to all cells and tissues under a dark condition and so provides better chances for more embryogenic cells to develop into calli. A combination of auxin and cytokinin at certain concentrations was used to increase the yields of callus induction and plant regeneration in one of our previous experiments (Khunchuay et al., 2009), but the regeneration efficiency was still not high enough. Hence, several combinations of different types and concentrations of auxin 
(NAA) and cytokinin (kinetin and BAP) were tried out in this study in order to find one that produces a satisfyingly high efficiency. Added to the culture media, these combinations were observed on how much they enhanced vetiver grass's callus induction and regeneration (Suratthani ecotype). A high callus induction efficiency will definitely benefit plant improvement via genetic transformation.

\section{Results and Discussion}

\section{Effects of PGRs in CIM on callus induction and plant regeneration}

After 4 weeks under a dark condition, axillary buds of vetiver grass cultured in different media produced calli of different quantities and qualities. These proliferated calli were then subcultured in fresh media of the same kind under the same condition for another 2 weeks. The results showed that NAA in combination with cytokinin had a direct effect on the efficiencies of callus induction and plant regeneration (Fig 1 . and Table 1.). Under the experimental conditions, the axillary buds grown in CIM2 and CIM5 showed the highest percentages of callus induction efficiency, 90 \pm 12.9 and $85 \pm 12.9 \%$ respectively. On the other hand, reducing the concentration of BAP in CIM from $1 \mathrm{mgL}^{-1}$ to $0.5 \mathrm{mgL}^{-1}$ or increasing the concentration of NAA from $2 \mathrm{mgL}^{-1}$ to 3 or 4 $\mathrm{mgL}^{-1}$ reduced the efficiencies of callus induction to $75 \pm 16.7$, $55 \pm 15.8$, and $52 \pm 14.2 \%$ respectively. Replacing BAP (CIM2) with kinetin (CIM5) at the same concentration did not make any differences statistically.

Although vetiver callus induction usually prefers a high ratio of auxin to cytokinin, an optimal combination of auxin and cytokinin is still needed to be determined for each kind of explant. Supplementing auxin in CIM is essential for inducing division and development of callus cells into embryogenic cells, especially for monocotyledon plants (Mendoza and Kaeppler, 2002; Shah et al., 2003; Can et al., 2008; Neibaur et al., 2008). However, a high concentration of auxin in a medium may prevent cell differentiation (Gray, 1996). Similar to this finding, our findings show that auxin at a high concentration (3-4 mgL $\mathrm{mAA}^{-1} \mathrm{NA}$ negatively affected both callus induction and plant regeneration of vetiver grass. An experiment with wheatgrass also showed a similar result (Wen et al., 2006).

Calli of similar sizes that were grown in every induction medium supplemented with a different combination of PGRs was transferred to a regeneration medium of MS supplemented with $1 \mathrm{mgL}^{-1} \mathrm{NAA}$ and $2 \mathrm{mgL}^{-1}$ BAP (PRM1). New shoots were sprouting in PRM1 4 weeks later. After six weeks of incubation, these calli showed different regeneration efficiencies. The differences in the regeneration efficiencies of calli grown in different CIMs followed the same direction as the differences in their callus induction efficiencies. Calli grown in an MS medium containing a combination of $2 \mathrm{mgL}^{-1} \mathrm{NAA}$ with $1 \mathrm{mgL}^{-1}$ kinetin (CIM5) or with $1 \mathrm{mgL}^{-1}$ BAP (CIM2) showed a relatively high frequency of plant regeneration, 85 or $80 \%$ respectively. In addition, calli grown in CIM5 gave the highest average number of shoots per callus (10.6 shoots) that was statistically higher than that given by calli grown in CIM2. The percentages of plantlets regenerated from 6-week old calli and the average number of shoots per callus are shown in Fig 2. and Table 1.

Our experimental results showed that callus induction of vetiver axillary bud really needed a suitable combination of PGRs at appropriate concentrations. It should be observed that, in the case of replacing BAP (CIM2) with kinetin
(CIM5), the efficiency of callus induction grown in CIM5 was not statistically different to that grown in CIM2. In contrast, CIM5 stimulated vetiver calli into generating shoot organs better than CIM2 did. Furthermore, the lower concentration of BAP in CIM1 also resulted in lower callus induction and regeneration. Thus, it can be concluded that a suitable combination of auxin and cytokinin and appropriate concentrations in the culture medium was necessary for enhancing callus induction and plant regeneration of vetiver grass.

Added to a culture medium, auxin in combination with cytokinin can induce endogenous PGRs that are components of the regulating processes of cell development into plant (Osborne et al., 2005). Auxin and cytokinin in a medium play antagonistic roles in the developmental processes of somatic embryogenesis. A study by Hwang et al. (2012) concluded that cytokinins promote cell differentiation via transcription factors and influence the expression of several target genes. Auxin also plays a critical role in the maintenance of shoot meristem (Su et al., 2011). In addition to regulating cell development, auxin in combination with cytokinin cause a $\mathrm{pH}$ shift of cell wall and may regulate the activity of cytokinin receptors on the cell membrane (Romanov et al., 2006). Moreover, auxin in the nodal stem of pea plant inhibits synthesis and accumulation of cytokinins (Tanaka et al., 2006), thus auxin may inhibit the excessive effects of cytokinins and regulates bud elongation.

\section{Cumulative effects of cytokinin in culture media on plant regeneration}

The numbers of yellow creamy calli grown from buds in CIM1, CIM2, and, CIM5 with different cytokinin concentrations were relatively higher than those grown in CIM3 and CIM4. To find out what kind of plant regeneration efficiency and number of shoots per callus different regeneration media gave, we cultured calli in 3 regeneration media-PRM1, PRM2, and PRM3. The calli incubated in these regeneration media produced green spots within 2 weeks and developed shoots after 4-6 weeks. The percentages of plant regeneration efficiency and the average number of shoots per callus grown in these regeneration media are presented in Table 2. Pictures of the regenerated plants are shown in Fig 3.

As can be seen in Table 2., the calli derived from the kinetin-free CIM2 medium showed a higher efficiency of plant regeneration when grown in PRM2 and PRM3 $(90 \pm 13.27$ and $95 \pm 11.2 \%$, respectively) which contained 1 and $2 \mathrm{mgL}^{-1}$ of kinetin compared to those grown in kinetinfree PRM1 $(75.0 \pm 17.7 \%)$. The average numbers of shoots per callus also followed the same trend as the plant regeneration efficiency $(9.4 \pm 0.4$ and $9.8 \pm 0.8$ shoots, respectively). Compared to each other, the growth results provided by PRM2 and PRM3 were not statistically different. In contrast to the case of CIM2, calli obtained from CIM1, which had a $50 \%$ lower concentration of BAP than CIM2, showed lower plant regeneration efficiencies when grown in all of the above regeneration media. Hence, it can be inferred that a low BAP concentration in a callus induction medium led to a low plant regeneration efficiency, even when kinetin was present in the regeneration medium, i.e. overall, kinetin in a regeneration medium did not promote growth if BAP in the callus induction medium was insufficient. The average number of shoots per callus grown in CIM1 also followed the same trend as their plant regeneration efficiency. Moreover, the average number of shoots produced from calli cultured in CIM1 was lower than those in CIM2 and CIM5 regardless of 
Table 1. Effects of different combinations and concentrations of plant growth regulators on callus induction and plant regeneration of Vetiveria zizanioides L. Nash cv. Suratthani

\begin{tabular}{|c|c|c|c|c|c|c|}
\hline \multirow[b]{2}{*}{ Medium } & \multicolumn{3}{|c|}{ Plant growth regulators } & \multirow{2}{*}{$\begin{array}{c}\text { Efficiency of } \\
\text { callus induction } \\
(\%)\end{array}$} & \multicolumn{2}{|c|}{$\mathrm{MS}+1 \mathrm{mgL}^{-1} \mathrm{NAA}+2 \mathrm{mgL}^{-1} \mathrm{BA}(\mathrm{PRM} 1)$} \\
\hline & $\begin{array}{c}\text { NAA } \\
\left(\mathrm{mgL}^{-1}\right)\end{array}$ & $\begin{array}{c}\mathrm{BAP} \\
\left(\mathrm{mgL}^{-1}\right)\end{array}$ & $\begin{array}{l}\text { Kinetin } \\
\left(\mathrm{mgL}^{-1}\right)\end{array}$ & & $\begin{array}{l}\text { Efficiency of plant } \\
\text { regeneration }(\%)\end{array}$ & $\begin{array}{l}\text { Average number of shoots } \\
\text { per callus (shoots) }\end{array}$ \\
\hline CIM1 & 2 & 0.5 & 0 & $75.0 \pm 16.7^{b}$ & $75.0 \pm 0.0^{\mathrm{abc}}$ & $9.6 \pm 0.9^{b}$ \\
\hline CIM2 & 2 & 1 & 0 & $90.0 \pm 12.9^{\mathrm{a}}$ & $80.0 \pm 11.2^{\mathrm{ab}}$ & $9.0 \pm 0.5^{\mathrm{bc}}$ \\
\hline CIM3 & 3 & 1 & 0 & $55.0 \pm 15.8^{\mathrm{c}}$ & $65.0 \pm 13.7^{\mathrm{bc}}$ & $9.8 \pm 0.2^{\mathrm{ab}}$ \\
\hline CIM4 & 4 & 1 & 0 & $52.5 \pm 14.2^{\mathrm{c}}$ & $60.0 \pm 13.7^{\mathrm{c}}$ & $8.6 \pm 0.1^{\mathrm{c}}$ \\
\hline CIM5 & 2 & 0 & 1 & $85.0 \pm 12.9^{\mathrm{ab}}$ & $85.0 \pm 13.7^{\mathrm{a}}$ & $10.6 \pm 1.1^{\mathrm{a}}$ \\
\hline
\end{tabular}

The different letters in each column represent a significant difference at $\mathrm{p} \leq 0.05$

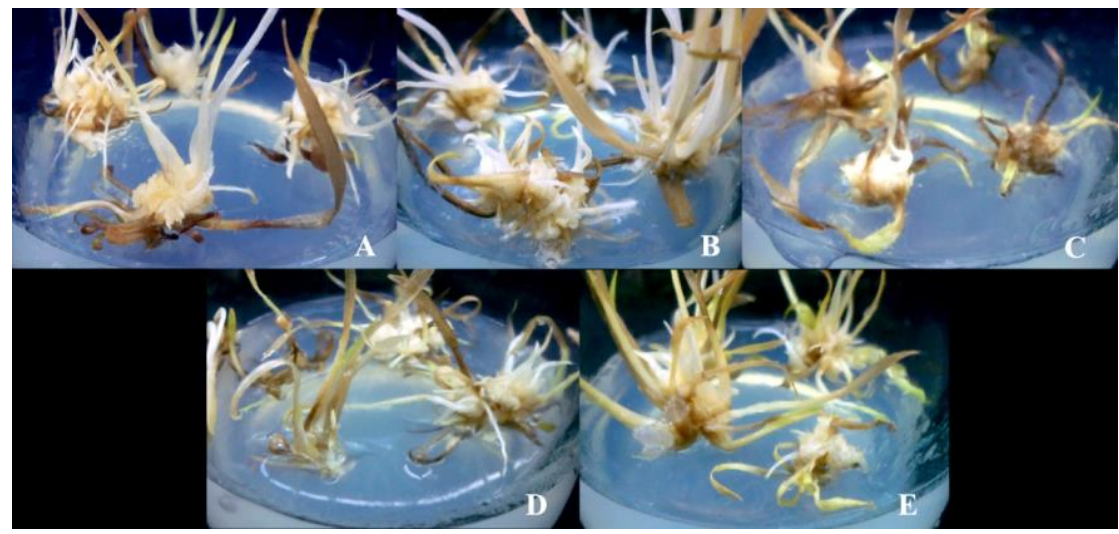

Fig 1. Calli of Vetiveria zizanioides L. Nash developed from axillary buds in different callus induction media (Table1.) under a dark condition for 6 weeks; Calli in pictures A to E were developed in CIM1 to CIM5, respectively.

Table 2. Regeneration efficiencies of calli of Vetiveria zizanioides L. Nash cv. Suratthani developed in CIM1-3 and then regenerated in PRM1-3.

\begin{tabular}{lccc}
\hline Callus induction medium & $\begin{array}{c}\text { Plant regeneration } \\
\text { medium }\end{array}$ & $\begin{array}{c}\text { Efficiency of plant } \\
\text { regeneration (\%) }\end{array}$ & $\begin{array}{c}\text { Average number of shoots per } \\
\text { callus (shoots) }\end{array}$ \\
\hline \multirow{3}{*}{ CIM1 } & PRM1 & $70.0 \pm 11.2^{\mathrm{c}}$ & $8.0 \pm 0.2^{\mathrm{c}}$ \\
& PRM2 & $70.0 \pm 11.2^{\mathrm{c}}$ & $8.4 \pm 0.8^{\mathrm{c}}$ \\
CIM2 & PRM3 & $75.0 \pm 0.0^{\mathrm{bc}}$ & $8.9 \pm 0.9^{\mathrm{bc}}$ \\
& PRM1 & $75.0 \pm 17.7^{\mathrm{bc}}$ & $8.7 \pm 0.5^{\mathrm{bc}}$ \\
& PRM2 & $90.0 \pm 13.7^{\mathrm{ab}}$ & $9.4 \pm 0.4^{\mathrm{ab}}$ \\
CIM5 & PRM3 & $95.0 \pm 11.2^{\mathrm{a}}$ & $9.9 \pm 0.7^{\mathrm{a}}$ \\
\hline \multirow{2}{*}{ The different letters in each column represent a significant difference at $\mathrm{p} \leq 0.05}$. & $80.0 \pm 11.2^{\mathrm{abc}}$ & $10.1 \pm 0.8^{\mathrm{a}}$ \\
\hline
\end{tabular}

The different letters in each column represent a significant difference at $\mathrm{p} \leq 0.05$.

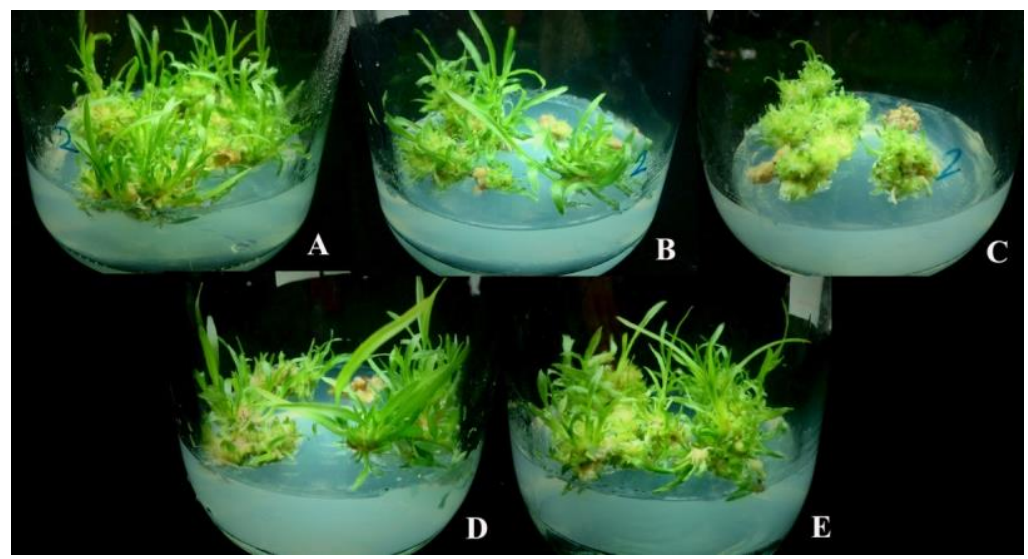

Fig 2. Plantlets of Vetiveria zizanioides L. Nash from calli regenerated in PRM1-an MS medium supplemented with $1 \mathrm{mgL}^{-1} \mathrm{NAA}$ and $2 \mathrm{mgL}^{-1} \mathrm{BAP}$-for 6 weeks of 16-h light/8-h dark photoperiods. Plantlets in pictures A to E were regenerated from calli developed in CIM1 to CIM5, respectively. 


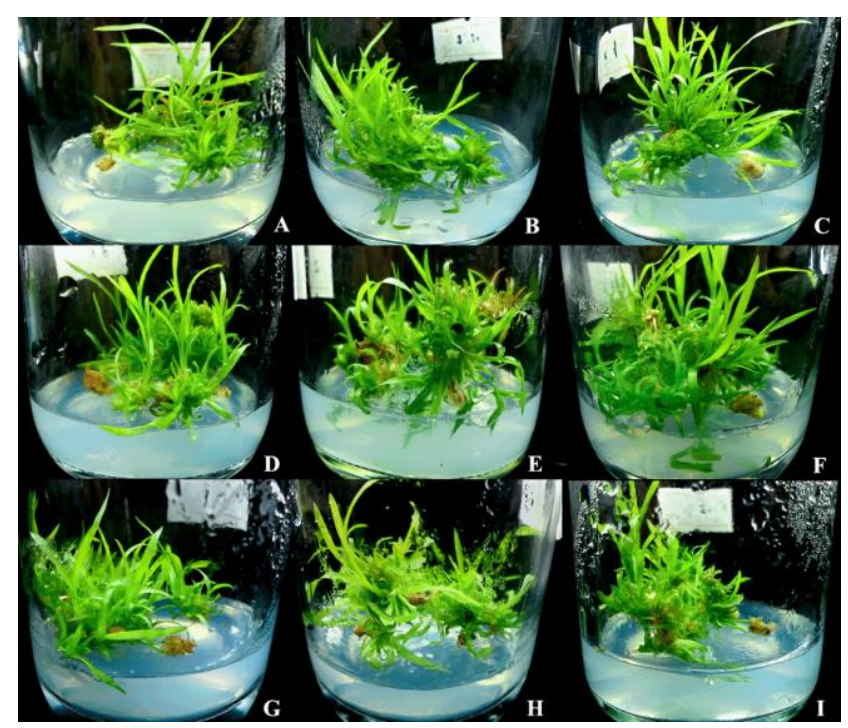

Fig 3. Plantlets of Vetiveria zizanioides L. Nash from calli developed in CIM1, CIM2, and CIM5 and regenerated in PRM1, PRM2, and PRM3 for 6 weeks of 16-h light/8-h dark photoperiods. Pictures A to C show plantlets from calli developed in CIM1 and regenerated in PRM1, PRM2, and PRM3 respectively. Pictures D to F show plantlets from calli developed in CIM2 and regenerated in PRM1, PRM2, and PRM3 respectively. Pictures G to I show plantlets from calli developed in CIM1 and regenerated in PRM1, PRM2, and PRM3, respectively.

the type of regeneration medium used. Although calli obtained from CIM1 were induced by a lower BAP concentration $\left(0.5 \mathrm{mgL}^{-1}\right)$, this lower concentration might be enough for callus induction but might not be enough for prolific plant regeneration. This kind of lower proliferation was also observed when the calli were further regenerated in PRM1, PRM2, and PRM3. For example, even though PRM3 contained $2 \mathrm{mgL}^{-1}$ of kinetin, the extra PGR was not able to enhance the regeneration of Calli from CIM1, whereas it was able to do so for calli from CIM2. The lower concentration of BAP cytokinin in CIM1 might have lowered the levels of endogenous PGRs of those calli, hence retarding plant regeneration. In contrast, calli obtained from CIM5 that contained kinetin instead of BAP showed high percentages of plant regeneration in PRM1 and PRM2. However, a higher concentration of $2 \mathrm{mgL}^{-1}$ kinetin in PRM3 reduced the regeneration efficiency of CIM5 calli. The average number of shoots per callus produced by calli obtained from CIM5 and grown in all of the regeneration media were 8-10 shoots.

It should be noted that both BAP and kinetin were needed in callus induction and regeneration media to induce more shoots, but kinetin, at a suitable level in either media or in both, induced shoot development better than BAP alone did. Interestingly, adding enough kinetin to either the callus induction medium or the regeneration medium alone both resulted in a high percentage of regeneration. For example, kinetin contained in CIM5 was enough to enhance calli development and regeneration in PRM1 that did not contain kinetin. In the same way, kinetin contained in PRM2 and PRM3 was enough to enhance the regeneration of calli cultured in CIM2 that did not contain kinetin. Thus, it seems that efficient calli development needs more than one kind of cytokinin.

Cytokinins transduced their signals by a receptor component system consisting of histidine kinase proteins and response regulators (Jenifer and Kieber 2008). More than one type of cytokinin receptor has been identified in various plant species (Du et al., 2007; Inoue et al., 2001; Suzuki et al., 2001; Yonekura-Sakakibara et al., 2004). The diversity of receptor structures restricts ligand binding activities to specific types of cytokinins (Spíchal et al., 2009) and may sequentially activate different developmental responses. Cytokinin actions in shoot proliferation are light-dependent (Baraldi et al., 1998). These PGRs involved in chlorophyll synthesis and enhancing starch content in the shoot apex (Werner et al., 2008). Evidence of enhanced sugar metabolism can be commonly found in shoot bud formation. Therefore, there have been reports that cytokinins affected various aspects of plant development, especially vascular development and organ formation (Mähönen et al., 2006; Barciszewski et al., 2007). In this study, BAP in combination with NAA in PRM1 (with no kinetin) did produce multiple shoots, but the shoots were small and failed to develop further. However, with the addition of kinetin, as in the case of PRM2 and PRM3, multiple shoots developed into mature plants. Kinetin can be added to the culture media in either the calli induction stage or plant regeneration stage and still be effective either way. Our results showed that kinetin acted in synergy with BAP and NAA in enhancing shoot proliferation. Different levels of exogenous kinetin in cell culture media at different developmental stages resulted in similar regeneration efficiencies because the cells might rebalance their endogenous PGRs by activating and/or depleting accumulation of other PGRs. Some evidence suggested that a certain type of grass may contain enough endogenous cytokinins for developmental embryogenesis (Wenck et al., 1998), therefore media containing exogenous cytokinins may inhibit calli development into somatic embryo. BAP and kinetin are aromatic cytokinins that differ only in the adenine substitution at N-6 position with benzyl ring or with furfural ring, respectively. This substitution leads to the unique biological activity of each cytokinin. Kinetin added to a culture medium stimulated transcription of RNA polymerase I in Arabidopsis (Barciszewski et al., 2007). This piece of evidence suggests that kinetin may have similar functions to BAP by acting as a common signal that regulates the transcription of proteins involving in the growth and development of plant cells. However, the activity of BAP is commonly known to be stronger than that of kinetin. Therefore, kinetin may attenuate the activity of BAP by modulating BAP's binding to its receptors. Our results showed that BAP induced a large number of shoots, but 
kinetin enhanced shoot development. In addition, the furfural ring in the kinetin structure can neutralize free radicals in cells (Barciszewski et al., 1997). The whole structure of kinetin also behaves as an antioxidant, inhibiting oxidation in vitro (Verbeka et al., 2000). For these reasons, kinetin has a potential for delaying plant senescence. According to Brathe et al., (2002), kinetin showed a slightly higher activity of DPPH scavenging and lipoxygenase inhibition than BAP did. Therefore, adding kinetin to a culture medium may not only have an effect on cell differentiation but also provides better cell characteristics.

\section{Materials and Methods}

\section{Plant materials}

Axillary buds of vetiver grass (Vetiveria zizanoides Lin Nash.) cv. Suratthani were used as an explant under an aseptic condition. The vetiver grass was obtained from the Land Development Department, Bangkok, Thailand.

\section{Effects of PGRs in CIM on callus induction and plant regeneration}

The axillary bud explants were cultured in 5 different callus induction media (CIM1-CIM5) (Table 1). The basal medium was an MS medium (Murashige and Skoog, 1962) containing $8.0 \%$ agar and $20 \mathrm{gL}^{-1}$ glucose supplemented with combinations of PGRs at various concentrations to make CIM1-CIM5. The $\mathrm{pH}$ values of all media were adjusted to 5.8 before sterilization. The explants were cultured in these media at $25 \pm 2{ }^{\circ} \mathrm{C}$ in a dark room. After 4 weeks, the calli were subcultured further under the same condition for another 2 weeks. The morphology of the proliferated calli were observed, and the frequencies of callus induction were recorded. Six-week-old calli were transferred to PRM1 - an MS plant regeneration medium containing $30 \mathrm{gL}^{-1}$ glucose and $1 \mathrm{mgL}^{-1}$ NAA plus $2 \mathrm{mgL}^{-1} \mathrm{BAP}$. Calli developed in each medium were incubated at $25 \pm 2{ }^{\circ} \mathrm{C}$ under 16 -h light/ 8 -h dark photoperiods for 6 weeks. The numbers of shoots per callus and the frequencies of shoot regeneration were recorded.

\section{Effects of cytokinin in culture media on plant regeneration}

Bud explants were cultured in three callus induction mediaCIM1, CIM2, and CIM5-that contained $0.5,1 \mathrm{mgL}^{-1} \mathrm{BAP}$ and $1 \mathrm{mgL}^{-1}$ kinetin, respectively. The samples were cultured in a dark room for 4 weeks and sub-cultured under the same condition for another 2 weeks. These calli were then transferred to three different plant regeneration mediaPRM1, PRM2, and PRM3. All of these media contained a fixed concentration of NAA $\left(1 \mathrm{mgL}^{-1}\right)$ and of BAP $\left(2 \mathrm{~mL}^{-1}\right)$ but each medium contained a different concentration of kinetin $-0,1$, and $2 \mathrm{mgL}^{-1}$, respectively. Calli were incubated at $25 \pm 2{ }^{\circ} \mathrm{C}$ under $16-\mathrm{h}$ light/8-h dark photoperiods for 6 weeks. Number of shoots per callus and frequency of shoot regeneration were recorded, and frequency of plant regeneration was estimated by counting. The percentages of callus induction and plant regeneration were calculated using the following equations ( 1 and 2 , respectively),

$$
\begin{aligned}
& \text { Callus induction }(\%)=\frac{\text { Number of buds that produced calli }}{\text { Total number of buds }} \times 100, \\
& \text { Plant regeneration }(\%)=\frac{\text { Number of calli that produced plantlets }}{\text { Total number of calli }} \times 100 .
\end{aligned}
$$

\section{Statistical analysis}

One-way ANOVA was used to test the significance of the effects of plant growth regulators on callus induction and plant regeneration. The means of the number of shoots per callus and of the frequencies of callus induction and plant regeneration were compared by using a least significant difference (LSD) test.

\section{Conclusions}

From this study, it was found that two media-an MS medium added with $2 \mathrm{mgL}^{-1} \mathrm{NAA}$ and $1 \mathrm{mgL}^{-1}$ BAP (CIM2) and an MS medium added with $2 \mathrm{mgL}^{-1} \mathrm{NAA}$ and $1 \mathrm{mgL}^{-1}$ kinetin (CIM5) - were suitable for callus induction of vetiver axillary buds. The calli induced in these two media, when transferred to an MS plant regeneration medium supplemented with $1 \mathrm{mgL}^{-1} \mathrm{NAA}$ and $2 \mathrm{mgL}^{-1}$ BAP (PRM1), provided the two highest plant regeneration frequencies. A suitable concentration of kinetin added to CIM or PRM media resulted in better shoot development from calli. Lack of kinetin in CIM could be compensated by its addition in PRM. BAP and kinetin acted synergistically to enhance shoot quality and quantity. A suitable concentration of auxin and suitable types and concentrations of cytokinin are important for promoting plant cell development in tissue culture.

\section{Acknowledgments}

Financial supports were partially provided by the National Research Council of Thailand (NRCT) and the National Nanotechnology Center (NANOTEC), National Science and Technology Development Agency (NSTDA), Ministry of Science and Technology, Thailand, through its program of Center of Excellence Network.

\section{References}

Adam RP, Nguyen S, Johnston DA, Park S, Provin TL Habte M (2008) Comparison of vetiver root essential oils from cleansed (bacteria-and fungus-free) VS. non-cleansed (normal) vetiver plants. Biochem Syst Ecol. 36:177-182.

Ali S, Iqbal J (2012) Influence of physical factors on callogenesis in sugarcane (Saccharum officinarum L.). Sci Int. 24:167-170.

Ashraf MF, Aziz MA, Kemat N, Ismail I (2014) Effect of cytokinin types, concentrations and their interactions on in vitro shoot regeneration of Chlorophytum borivilianum Sant. \& Fernandez. Electron J Biotechnol. 17:275-279.

Baraldi R, Rossi1 F, Lercari B (1988) In vitro shoot development of Prunus GF 655-2: interaction between light and benzyladenine. Physiol Plant.74:440-443.

Barciszewski J, Massino F, Clark BFC (2007) Kinetin- A muitiactive molecule. Int J Biol Macromol. 40:182-192.

Barciszewski J, Siboska GE, Pedersen BO, Clark BFC, Rattan SIS (1997) A mechanism for the in vivo formation of $\mathrm{N}^{6}$ furfuryladenine, kinetin, as a secondary oxidative damage product of DNA. FEBS Lett. 414:457-460.

Bhuiyan MDNI, Chowdhury JU, Begum J (2008) Essential oil in roots of Vetiveria zizanioides (L) Nash. Ex small from Bangladesh. Bangl J Bot. 37(2):213-215.

Bhushan B, Kumar SS, Tanuja S, Lalit S, Hema A (2013) Vetiveria zizanioides (Linn.) Nash : A pharmacological overview. Int Res J Pharm. 4(7):18-20.

Bråthe A, Andresen G, Gundersen LL, Malterud KE, Rise F (2002) Antioxidant activity of synthetic cytokinin analogues: 6-alkynyl- and 6-alkenylpurines as novel 15-lipoxygenase inhibitors. Bioorgan Med Chem. 10:1581-1586. 
Can E, Celiktas N, Hatipoglu R (2008) Effect of auxin type and concentrations in different media on the callus induction and shoot formation of crested wheatgrass (Agropyron cristatum (L.) Gaertn). Biotechnol Biotec EQ. 22(3):782-786.

Cedo OML, Licas MJN, Zara RR, Guzman CC (2012) Enhanced plantlet regeneration and in vitro root production in vetiver [Vetiveria zizanioides (L.) Nash]. Philipp Agric Sci. 95(4):344-351.

Du L, Jiao F, Chu J, Jin G, Chen M \& Wu P (2007) The twocomponent signal system in rice (Oryza sativa L.): a genomewide study of cytokinin signal perception and transduction. Genomics 89:697-707.

Gray DJ (1996) Nonzygotic embryogenesis. In: Trigiano RN, Gray DJ (eds) Plant tissue culture concepts and laboratory exercises. CRC Press, Boca Raton.

Habiba SU, Shimasaki K, Ahasan MM, Alam MM (2014) Effect of different cytokinins on in vitro organogenesis in protocormlike bodies (PLBs) of Epidendrum "Rouge Star No.8”. Middle East J Sci Res. 21(10):1843-1847.

Hwang I, Sheen J, Müller B (2012) Cytokinin signaling networks. Annu Rev Plant Biol 63:353-380.

Inoue T, Higuchi M, Hashimoto Y, Seki M, Kobayashi M, Kato T, Tabata S, Shinozaki K \& Kakimoto T (2001) Identification of CRE1 as a cytokinin receptor from Arabidopsis. Nature. 409:1060-1063.

Jennifer PC, Kieber JJ (2008) Cytokinin signaling: twocomponents and more. Trends Plant Sci. 13:85-92.

Khunchuay C, Phuwiwat W, Sompornpailin K (2009) Callus induction and plant regeneration from Vetiveria zizanioides (L.) Nash. Paper presented at the 21st Annual meeting and international conference of the thai society for biotechnology: Queen Sirikit National Convention Center, Bangkok, Thailand, 24-25 September 2009.

Koul O, Walia S, Dhaliwal GS (2008) Essential oils as green pesticides: potential and constraints. Biopestic Int. 4(1):63-84.

Leaungvutiviroj C, Piriyaprin S, Limtong P, Sasaki K (2010) Relationships between soil microorganisms and nutrient contents of Vetiveria zizanioides (L.) Nash and Vetiveria nemoralis (A.) Camus in some problem soils from Thailand. App Soil Ecolo. 46:95-102.

Mähönen AP, Bishopp A, Higuchi $M$, Nieminen KM, KinoshitavK, Törmäkangas K, Ikeda Y, Oka A, Kakimoto T, Helariutta Y (2006) Cytokinin signaling andits inhibitor AHP6 regulate cell fate during vascular development. Science 311:94-98.

Mao L, Henderson G, Laine RA (2004) Germination of various weed species in response to vetiver oil and nootkatone. Weed Technol. 18(2):263-267.

Mendoza MG, Kaeppler HF (2002) Auxin and sugar effects on callus induction and plant regeneration frequencies from mature embryos of wheat (Triticum aestivum L.). In Vitro Cell Dev Biolo. 38:39-45.

Minh VV, Khoa LV (2009) Phytoremediation of cadmium and lead contaminated soil types by vetiver grass. VNU J Sci. 25:98-103.

Mok MC (1994) Cytokinins and plant development-an overview. In: Mok DWS, Mok MC (eds) Cytokinin: chemistry, activity and function, CRS Press, Boca Raton.

Murashige T, Skoog F (1962) A revised medium for rapid growth and bioassays with tobacco tissue cultures. Physiol Plant. 15:473-498.

Neibaur I, Gallo M, Altpeter F (2008) The effect of auxin type and cytokinin concentration on callus induction and plant regeneration frequency from immature inflorescence segments of seashore paspalum (Paspalum vaginatum Swartz). In Vitro Cell Dev Biol. 44:480-486.

Osborne DJ, Mc-Manus MT (2005) Hormones, Signals and target cells in Plant development. Cambridge University Press, United States of America.

Redig P, Shaul O, Inze D, Montagu MV, Onckelen HV (1996) Levels of endogenous cytokinins, indole-3-acetic acid and abscisic acidduring the cell cycle of synchronized tobacco BY2 cells. FEBS Lett. 391:175-180.

Romanov GA, Lomin SN, Schmülling T (2006) Biochemica characteristics and ligand-binding properties of Arabidopsis cytokinin receptor AHK3 compared to CRE1/AHK4 as revealed by a direct binding assay. J Exp Bot. 57:4051-4058.

Sahoo KK, Tripathi AK, Pareek A, Sopory SK, Singla-Pareek SL (2011) An improved protocol for efficient transformation and regeneration of diverse indica rice cultivars. Plant Methods. 7:49.

Sangduen N, Prasertsongskun S (2009) Regeneration and application: from suspension cultured-derived inflorescences of Vetiveria zizanioides (L.) Nash. to selection of herbicideresistant cell. AU J T. 12(3):135-148.

Sangeetha D, Stella D (2012) Screening of microbial activity of vetiver extracts aganst certain pathogenic microorganisms. Int J Pham Biol Arch. 3(1):197-203.

Shah MI, Jabeen M, Ilahi I (2003) In vitro callus induction, its proliferation and regeneration in seed explants of wheat (Triticum aestivum L.) var. Lu-26S. Pak J Bot. 35(2):29-217.

Soni R, Carmichael JP, Shah ZH, Murray JAH (1995) A family of cyclin $\mathrm{D}$ homologs from plants differentially controlled by growth regulators and containing the conserved retinoblastoma protein interaction motif. Plant Cell. 7:85-103.

Spíchal L, Werner T, Popa I, Riefler M, Schmülling T, Strnad M (2009) The purine derivative PI-55 blocks cytokinin action via receptor inhibition. FEBS J. 276: 244-253.

Su YH, Liu YB, Zhang, XS (2011) Auxin-Cytokinin interaction regulates meristem development. Mol Plant. 4(4):616-625.

Sudhishri S, Dass A, Lenka NK (2008) Efficacy of vegetative barriers for rehabilitation of degraded hill slopes in eastern India. Soil Till Res. 99:98-107.

Sun P, Zhang W, Yin F, Zhao X, Lui J, Chen Y, Lui S (2014) Biogas production potential of transgenic Vetiveria zizanioides in mesophilic bath anaerobic digestion. Sci Res Essay. 9(9):293-296

Suzuki T, Miwa K, Ishikawa K, Yamada H, Aiba H \& Mizuno T (2001) The Arabidopsis sensor His-kinase, AHK4, can respond to cytokinins. Plant Cell Physiol. 42,107-113

Tanaka M, Takei K, Kojima M, Sakakibara H, Mori H (2006) Auxin controls local cytokinin biosynthesis in the nodal stem in apical dominance. Plant J. 45:1028-1036.

Verbeke P, Siboska GE, Clark BFC, Rattan SIS (2000) Kinetin inhibits protein oxidation and glycoxidation in vitro. Biochem Biophys Res Commun. 276:1265-1270.

Wen HX, Hua WJ, Bo XC, Gui MF, Feng YJ (2006) Plant regeneration from immature inflorescence culture and genetic transformation of wheat grass (Agropyron cristatumXA desertorum cv. Hycrest-Mengnong). Agric Sci China. 5(9):648-654.

Wenck AR, Conger BV, Trigiano RN, Sams CE (1998) Inhibition of somatic embryogenesis in Orchardgrass by endogenous cytokinins. Plant Physiol. 88:990-992.

Werner T, Holst K, Pörs Y, Guivarc'h A, Mustroph A, Chriqui D, Grimm B, Schmülling T (2008) Cytokinin deficiency causes distinct changes of sink and source parameters in tobacco shoots and roots. J Exp Bot. 59:2659-2672.

Yonekura-Sakakibara K, Kojima M, Yamaya T \& Sakakibara H (2004) Molecular characterization of cytokinin-responsive histidine kinases in maize. Differential ligand preferences and response to cis-zeatin. Plant Physiol. 134:1654-1661.

Zhenrang M, Bingbing Y, Hanping X (2006) Effecting factors of somatic embryogenesis and plant regeneration in vetiver. J Trop Subtrop Bot. 14(1):55-60. 